\title{
Effect of viscosity of a liquid membrane containing oleyl alcohol on the pertraction of butyric acid
}

\author{
${ }^{a}$ Marek Blahušiak*, a Ján Marták, ${ }^{a, b}$ Fernando Miranda, ǎ́tefan Schlosser, \\ bJosé A. Teixeira
}

\author{
${ }^{a}$ Institute of Chemical and Environmental Engineering, Faculty of Chemical and Food Technology, \\ Slovak University of Technology in Bratislava, 81237 Bratislava, Slovakia \\ ${ }^{\mathrm{b}}$ Institute for Biotechnology and Bioengineering, Centre of Biological Engineering, University of Minho, \\ 4710-057 Braga, Portugal
}

Received 15 June 2012; Revised 30 December 2012; Accepted 31 December 2012

\begin{abstract}
Solvent formulation is important in the optimization of the mass-transfer through supported liquid membranes (SLM) in pertraction and membrane extraction. Oleyl alcohol (OA) is frequently used as the solvent or diluent in the extraction of carboxylic acids. A disadvantage of OA is its relatively high viscosity of $28.32 \mathrm{mPa} \mathrm{s}$ at $25^{\circ} \mathrm{C}$. This can be decreased by the application of a less viscous OA diluent, e.g. dodecane. The relationship between the ratio of the distribution coefficient of butyric acid (BA), $D_{\mathrm{F}}$, and the viscosity of $\mathrm{OA}$-dodecane solvents, $\mu$, as extraction and transport characteristics, and the overall mass-transfer coefficient, $K_{\mathrm{p}}$, through SLMs was analyzed. Dependence of the $D_{\mathrm{F}} / \mu$ ratio on the OA concentration showed a maximum at the OA concentration of 15 mass $\%$ to 30 mass $\%$. The OA concentration dependence of $K_{\mathrm{p}}$ for SLMs exhibited also a maximum at about 30 mass $\%$ and 20 mass $\%$ of $\mathrm{OA}$ at the BA concentration driving force of 0.12 $\mathrm{kmol} \mathrm{m}^{-3}$ and $0.3 \mathrm{kmol} \mathrm{m}^{-3}$, respectively. Shifting of the maximum in $K_{\mathrm{p}}$ dependences towards lower OA concentrations by increasing the BA concentration driving force is in agreement with the $D_{\mathrm{F}} / \mu$ ratio dependence. Using pure OA as the solvent or diluent is not preferable and a mixture of a low viscosity diluent with the OA concentration below 40 mass $\%$ should be used. The presented results show the potential of the $D_{\mathrm{F}} / \mu$ ratio in the screening and formulation of solvents in extraction and SLM optimization.
\end{abstract}

(c) 2013 Institute of Chemistry, Slovak Academy of Sciences

Keywords: pertraction, extraction, butyric acid, oleyl alcohol, dodecane, supported liquid membrane, viscosity effect

\section{Introduction}

Butyric acid (BA) has numerous applications in food, cosmetic and pharmaceutical industries. It is also a potential building block for organic synthesis in biorefineries. However, fermentation of butyric acid has a disadvantage of strong inhibition by the product (Wu \& Yang, 2003; Zigová et al., 1999, 2000). Online separation of BA from the fermentation solution by an extractive technique is a possible solution of this prob- lem (Evans \& Wang, 1990; Hatzinikolaou \& Wang, 1992; Marták et al., 2003; Vandák et al., 1997; Wu \& Yang, 2003; Zigová et al., 1999). Various solvents and approaches have been employed in this process with different success. The application of traditional acid extractants such as amines (Bilgin et al., 2006; Li et al., 2002; Sabolová et al., 2001; Shan et al., 2006; Vandák et al., 1997; Wu \& Yang, 2003; Zigová et al., 1996, 1999) or TBP (Ingale \& Mahajani, 1994, 1996) for BA extraction can be found in literature.

*Corresponding author, e-mail: marek.blahusiak@stuba.sk 
Equilibrium BA partitioning with trioctylamine in various diluents was compared by Bilgin et al. (2006), who showed increased partitioning when alcohols were used as diluents. Some authors used oleyl alcohol (OA) as the amine diluent in the extraction of BA (Bilgin et al., 2006; Hatzinikolaou \& Wang, 1992; Keshav et al., 2009; Wu \& Yang, 2003; Zigová et al., 1999, 2000). A detailed extraction equilibrium study on the system $\mathrm{OA}-\mathrm{H}_{2} \mathrm{O}-\mathrm{BA}$ was presented (Bilgin, 2006). Enhancement of the fermentation by product (butanol or butyric acid) removal using extraction with a mixed OAdecanol solvent was presented (Evans \& Wang, 1988, 1990). Membrane based solvent extraction (MBSE) by solvents composed of Alamine 336 and an alcohol diluent was used for the removal of sulfuric acid, acetic acid, 5-hydroxymethyl furfural, and furfural from corn stover hydrolyzate by dilute sulfuric acid (Grzenia et al., 2012a, 2012b). It was found that the oleyl alcohol diluent is preferable to octanol which is toxic in the fermentation step.

Recently, hydrophobic ionic liquids (ILs) have been identified as good extractants of carboxylic acids (Blahušiak et al., 2011; Marták \& Schlosser, 2007, 2008). Separation and concentration of LA and BA by the pertraction through a supported liquid membrane (SLM) containing phosphonium IL has been studied by Marták et al. (2008, 2011). SLM exhibited high stability during one week of continual operation. A hybrid fermentation-pertraction process with SLM containing amine or IL solutions in the membrane phase has been simulated by Blahušiak et al. (2010).

General problem of pure ionic liquids in the separation processes is their relatively high viscosity hindering their mass-transfer capability. Viscosity can be decreased by an addition of a low molecular diluent to IL to form a two component extractant (carrier)-diluent solvent. Significant decrease of viscosity of phosphonium Cyphos IL-104 and ammonium IL after their dilution with dodecane has been shown (Blahušiak et al., 2011). Dodecane solutions of IL, $0.724 \mathrm{kmol} \mathrm{m}^{-3}$, were used as the membrane phase in SLM by Evans and Wang (1990) and Marták et al. (2011, 2008). Marták et al. (2011) compared the mass-transfer in the pertraction through an SLM formed by pure dodecane and a dodecane solution of IL.

Application of $\mathrm{OA}$ in solvents has been widely studied (Bilgin, 2006; Evans \& Wang, 1990; Grzenia et al., 2012a, 2012b; Keshav et al., 2009; Wu \& Yang, 2003). A disadvantage of OA is its relatively high viscosity, $28.32 \mathrm{mPa}$ s, although it is not as high as the viscosity of ILs. OA-dodecane mixtures may combine beneficial properties of both components and can be possibly used as diluents of extractants including ILs. The aim of the presented work was to study the properties of dodecane-OA solvents and SLMs at various concentrations of OA. The relationship between the solvent viscosity, equilibrium partitioning, and mass-transfer properties was ana- lyzed to optimize the composition of the membrane phase.

\section{Theoretical}

Detailed mathematical models and mass-transfer analysis in systems with pertraction through SLM can be found in literature (Kertész et al., 2004; Marták et al., 2011, 2008). Molar flux of BA from the feed to the stripping solution through an SLM through a surface element in the membrane contactor is described by the relation

$$
\mathrm{d} \dot{n}_{\mathrm{p}}=K_{\mathrm{p}} \varepsilon\left(c_{\mathrm{F}}-c_{\mathrm{FR}}\right) \mathrm{d} A_{\mathrm{g}}
$$

where $\mathrm{d} \dot{n}_{\mathrm{p}}$ is molar flux of BA in membrane contactor element of surface $\mathrm{d} A_{\mathrm{g}}, K_{\mathrm{p}}$ is overall mass-transfer coefficient, $\varepsilon$ is porosity of membrane support, $c_{\mathrm{F}}$ is BA concentration in feed, and $c_{\mathrm{FR}}$ is the theoretical concentration of BA in the feed phase at the membrane surface related to the concentration of undissociated $\mathrm{BA}$ in the stripping solution which is given as

$$
c_{\mathrm{FR}}=c_{\mathrm{R}} \frac{D_{\mathrm{R}}}{D_{\mathrm{F}}}
$$

where the distribution coefficient on the feed side, $D_{\mathrm{F}}$, is defined as ratio of equilibrium concentrations in membrane phase at feed side and in feed phase

$$
D_{\mathrm{F}}=\frac{c_{\mathrm{M}}}{c_{\mathrm{F}}}
$$

In case of an alkali excess in the stripping solution, the whole amount of BA is in the dissociated form as a salt, $c_{\mathrm{R}}=c_{\mathrm{FR}}=0$. After neglecting the BA concentration dependence of $K_{\mathrm{p}}$ for counter-current flow of the feed and the stripping phase in the membrane contactor, the integral form of Eq. (1) follows

$$
\dot{n}_{\mathrm{p}}=K_{\mathrm{p}} \varepsilon A_{\mathrm{g}} c_{\mathrm{F}, \mathrm{ls}}
$$

where the mean logarithmic concentration driving force, $c_{\mathrm{F}, \mathrm{ls}}$, is calculated as

$$
c_{\mathrm{F}, \mathrm{ls}}=\frac{c_{\mathrm{F}, \text { in }}-c_{\mathrm{F}, \mathrm{out}}}{\ln \frac{c_{\mathrm{F}, \text { in }}}{c_{\mathrm{F}, \mathrm{out}}}}
$$

Overall resistance to mass-transfer in the pertraction comprises several partial resistances: $R_{\mathrm{F}}-$ masstransfer resistance at the feed side, $R_{\mathrm{M}}$ - mass-transfer resistance in the membrane, $R_{\mathrm{R}}$ - mass-transfer resistance at the stripping side (Fig. 1). For systems with planar geometry of the membrane and supposed equilibrium at the phase interface, the governing equation is

$$
R_{\mathrm{p}}=\frac{1}{K_{\mathrm{p}}}=R_{\mathrm{F}}+R_{\mathrm{M}}+R_{\mathrm{R}}=\frac{\varepsilon}{k_{\mathrm{F}}}+\frac{1}{k_{\mathrm{M}} D_{\mathrm{F}}}+\frac{\varepsilon}{k_{\mathrm{R}} D_{\mathrm{F}}}
$$




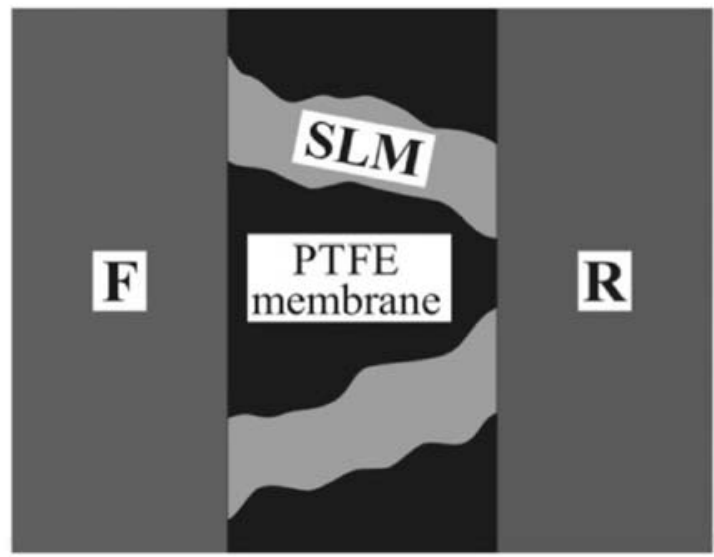

$\mathrm{b}$

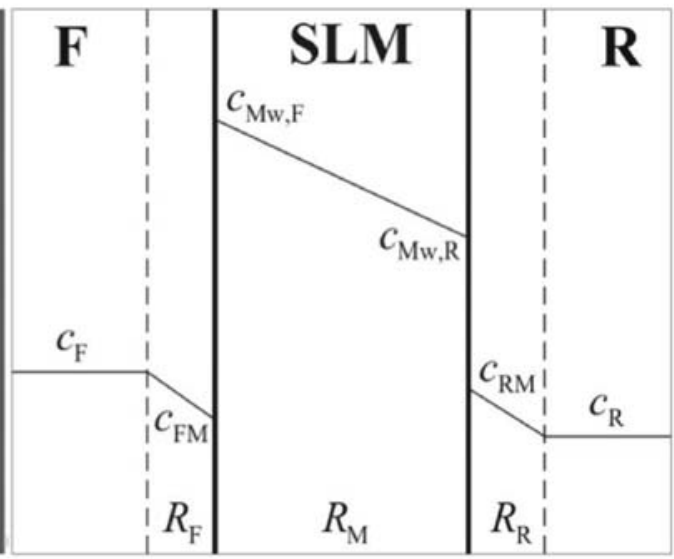

Fig. 1. Scheme of three-phase pertraction through SLM (a) and the related concentration profile (b). F - Feed, SLM - supported liquid membrane, $\mathrm{R}$ - stripping solution.

where $k_{\mathrm{F}}, k_{\mathrm{M}}$, and $k_{\mathrm{R}}$ are individual mass-transfer coefficient of BA at feed side, in membrane, and at the stripping side, respectively. Resistance of the SLM, $R_{\mathrm{M}}$, significantly contributes to the overall masstransfer resistance and thus also significantly influences the value of the overall mass-transfer coefficient, $K_{\mathrm{p}}$ (Evans \& Wang, 1990; Marták et al., 2011, 2008). Therefore, optimization of the SLM composition decreasing this resistance is required. From Eq. (6) follows that the product of the mass-transfer coefficient, $k_{\mathrm{M}}$, and the distribution coefficient has to be maximized to decrease the resistance of the membrane. Coefficient $k_{\mathrm{M}}$ can be expressed by the following equation

$$
k_{\mathrm{M}}=\frac{\varepsilon \mathscr{D}_{\mathrm{BA}}}{\tau \delta_{\mathrm{w}}}
$$

where $\tau$ is tortuosity and $\delta_{\mathrm{w}}$ is the thickness of the support. The diffusion coefficient of $\mathrm{BA}, \mathscr{D}_{\mathrm{BA}}$, in the solvent phase is proportional to the reciprocal value of its viscosity as follows from the Wilke-Chang equation (Reid et al., 1977; Wilke \& Chang, 1955). Thus, in the first approximation, optimization of the membrane phase properties represents a search for the solvent composition in SLM maximizing the ratio of the distribution coefficient of the solute and the dynamic viscosity of the solvent as the optimization parameters

$$
\frac{D_{\mathrm{F}}}{\mu}=\max
$$

\section{Experimental}

To prepare aqueous solutions of butyric acid (BA), $99.5 \%$ BA (Fluka, Switzerlad) was used as received. Dodecane $\left(M=170.3 \mathrm{~kg} \mathrm{kmol}^{-3}, 98 \%\right.$ purity, Fluka, Switzerland) and oleyl alcohol (85\% purity, Merck, Germany) were used to prepare solvents without further conditioning. Density and dynamic viscosity of
Table 1. Properties of pure OA and dodecane

\begin{tabular}{lcc}
\hline Component & $\rho /\left(\mathrm{kg} \mathrm{m}^{-3}\right)$ & $\mu /(\mathrm{mPa} \mathrm{s})$ \\
\hline OA & 845.1 & 28.32 \\
dodecane & 746.3 & 1.38 \\
\hline
\end{tabular}

pure dodecane and oleyl alcohol are presented in Table 1. Pure oleyl alcohol, dodecane, and their mixtures contained a negligible amount of water $(<0.01$ mass \%) after their saturation at $25^{\circ} \mathrm{C}$. Sodium hydroxide was purchased from Mikrochem (Slovakia).

The L/L extraction equilibrium measurements are out scope of this paper and the method is described in detail elsewhere (Marták \& Schlosser, 2008). Pertraction experiments were carried out using SLM immobilized on a PTFE microporous film of the type 11807 (Sartorius, Germany) with the thickness of $66.4 \mu \mathrm{m}$, the mean pore diameter of $0.2 \mu \mathrm{m}$, and the porosity of $70 \%$. Various SLMs were prepared by impregnation of the support film with 15 mass $\%, 22.5$ mass $\%, 30$ mass \%, 50 mass \%, 75 mass $\%$ dodecane solutions and pure OA in a spiral channel flat sheet module, Fig. 2, described in more detail by Kertész et al. (2004). Basic characteristics of the module are listed in Table 2.

For the impregnation of a selected membrane phase, the channel was continuously filled with the solvent (membrane phase) from the feed inlet side with closed stripping phase inlet and outlet until no bubbles were present in the feed outlet. Then, the feed outlet side was closed and the stripping inlet was opened to push the organic phase through the PTFE microporous film and to remove the previous SLM phase from its pores. The solvent was pushed through the microporous film to the stripping side channel until no bubbles were observed in the solvent phase leaving the stripping side inlet. Finally, only the stripping side 
a

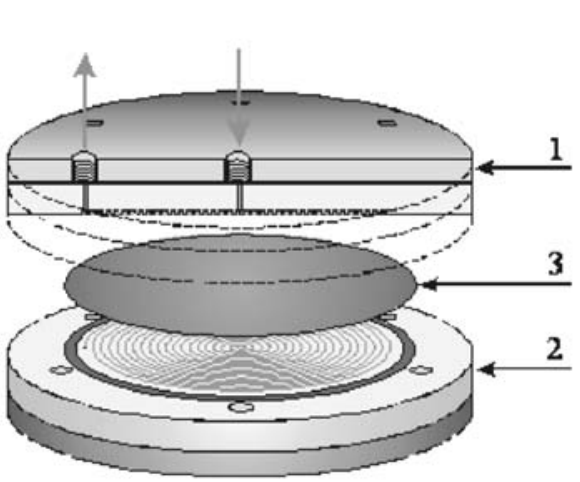

b

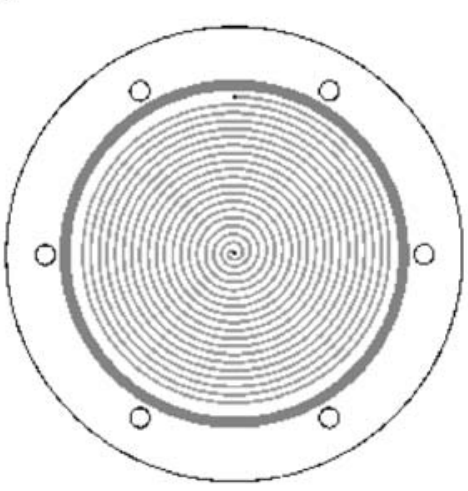

Fig. 2. Spiral channel module with a supported liquid membrane (a). Top view of the Archimedes spiral channel in the PTFE block (b). 1 - Aluminium block with inlet and outlet of the feed phase (symmetrically placed inlet and outlet connections for the stripping solution on the other side of the module), 2 - PTFE block, 3 - SLM-microporous film with liquid membrane in the pores.

Table 2. Characteristics of the membrane module and PTFE membrane support

\begin{tabular}{lc}
\hline Dimensions & Value \\
\hline Module diameter/mm & 120 \\
Membrane support diameter $/ \mathrm{mm}$ & 90 \\
Membrane support thickness $/ \mu \mathrm{m}$ & 66.4 \\
Outer diameter of spiral/mm & 82.2 \\
Channel depth/mm & 0.25 \\
Channel width/mm & 1.42 \\
Channel mean length/m & 2.48 \\
Channel hydraulic diameter $/ \mathrm{mm}$ & 0.425 \\
Channel volume/cm & \\
Surface area of the support in $\mathrm{channel}^{3} A_{\mathrm{g}} / \mathrm{cm}^{2}$ & 0.88 \\
Support porosity, $\varepsilon$ & 35.15 \\
Mean pore size/ $\mu \mathrm{m}$ & 0.7 \\
Effective membrane area, $A_{\mathrm{g}} \varepsilon / \mathrm{cm}^{2}$ & 0.2 \\
& 24.60 \\
\hline
\end{tabular}

inlet was left open and the stripping side channel was filled with the organic phase until no bubbles came out. Ten minutes after the module was completely filled with the organic phase, the impregnation was considered to be complete and the excess of the organic phase was removed from the channels by deionized water pumped into both channels of the module for at least one hour until no more solvent drops were observed in the washing water.

Design of the experimental setup is described in more detail in literature (Kertész et al., 2004; Marták et al., 2008). Circulation mode was used for the feed and stripping solutions (Kertész et al., 2004). The whole equipment, with the feed and the stripping solutions, was placed in a box with air tempered at $25^{\circ} \mathrm{C}$. Initial volumes of the feed and stripping phases were $500 \mathrm{~cm}^{3}$ and $75 \mathrm{~cm}^{3}$, respectively. Volumetric flowrates of the feed and stripping solutions were determined precisely prior and after each pertraction experiment by pumping of washing water from the beaker on the balance. The respective val- ues were in the interval of $0.5-0.7 \mathrm{~cm}^{3} \mathrm{~min}^{-1}$ and $0.4-0.41 \mathrm{~cm}^{3} \mathrm{~min}^{-1}$ in the feed and stripping channel, respectively, with the corresponding flow velocities of $2.1-3.2 \mathrm{~cm} \mathrm{~s}^{-1}$ and $1.8-1.81 \mathrm{~cm} \mathrm{~s}^{-1}$. For each membrane phase, pertraction experiments were conducted with three feed solutions of the BA concentrations of $0.59 \mathrm{kmol} \mathrm{m}^{-3}, 0.39 \mathrm{kmol} \mathrm{m}^{-3}$, and $0.147 \mathrm{kmol} \mathrm{m}^{-3}$ typically for $4 \mathrm{~h}$ for each feed phase with the collection of samples from the feed and stripping solutions in 60-90 min intervals. Pertraction with the feed of $0.59 \mathrm{kmol} \mathrm{m}^{-3}$ of BA was done twice for each SLM, at the beginning and at the end of the experiment, to check the SLM integrity over time. $\mathrm{pH}$ in the feed inlet and outlet streams was well below $\mathrm{p} K_{\mathrm{a}}$ of $\mathrm{BA}$ (4.82), guaranteeing that only undissociated BA was present in the feed. In the stripping solution, a minimum $\mathrm{NaOH}$ excess of $30 \%$ was maintained during the pertraction experiments to achieve the dissociation of the whole amount of BA. The $K_{\mathrm{p}}$ value for each feed was estimated from Eqs. (4) and (5) as the mean of the $K_{\mathrm{p}}$ values of each two samplings.

Concentration of butyric acid in the aqueous phases of the experiments was analyzed by capillary isotachophoresis using an analyzer EA 100 (Villa, Slovakia). The $10 \mathrm{~mol} \mathrm{~m}^{-3}$ histidine chloride buffer with pH 6 containing 0.1 mass $\%$ of methylhydroxyethylcellulose was used as the leading electrolyte and 5 $\mathrm{mol} \mathrm{m} \mathrm{m}^{-3}$ of histidylmorpholineethane-sulfonate as the termination electrolyte.

Dynamic viscosity of the membrane phases was measured by a precision rotating rheometer Kinexus (Malvern, UK) using the cone and plate method.

\section{Results and discussion}

Extraction equilibrium and viscosity measurements for various OA-dodecane mixtures are presented in Figs. 3 and 4a. More extensive data are beyond the scope of this paper and the respective publication is in preparation. A slight increase of the BA 
a

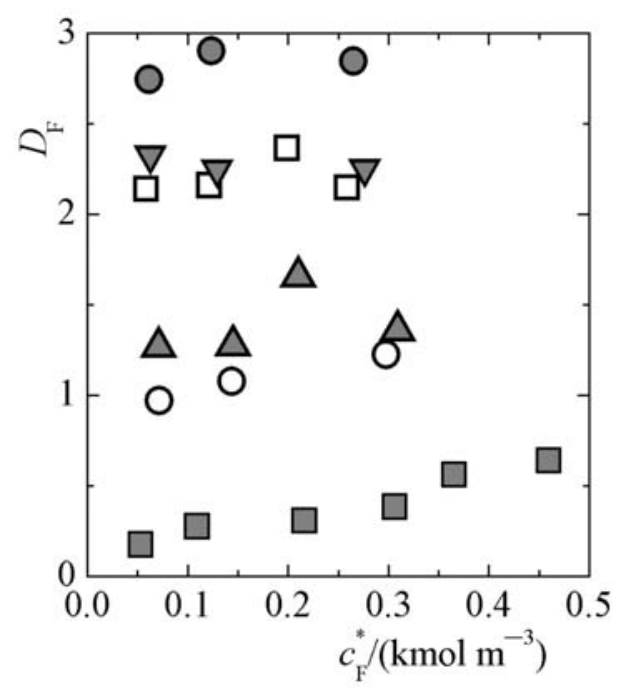

b

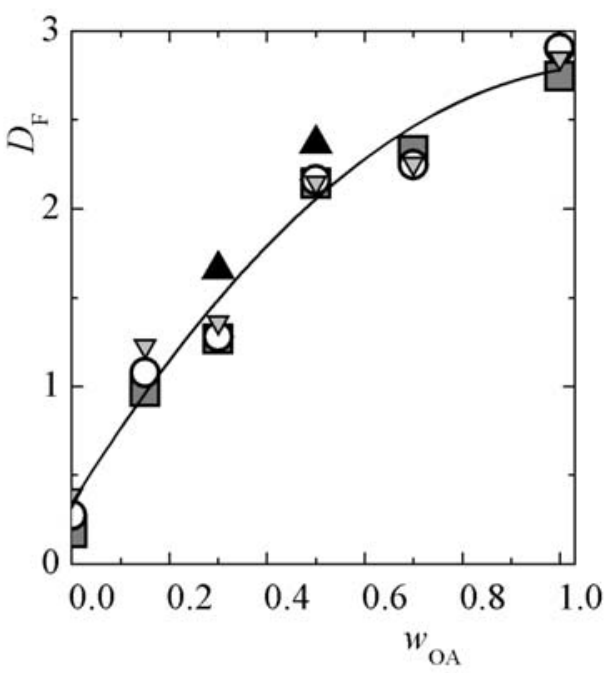

Fig. 3. Dependence of the distribution coefficient on the equilibrium BA concentration in BA extraction with solvents containing

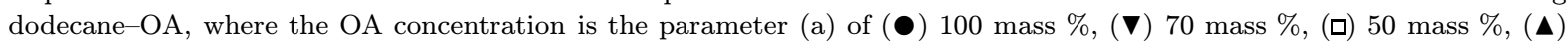
30 mass \%, (O) 15 mass \%, ( 0 ) mass \% and on the mass fraction of oleyl alcohol in pure solvent with equilibrium BA concentration as the parameter $(\mathrm{b})$ of $(\boldsymbol{\nabla}) \sim 0.06 \mathrm{kmol} \mathrm{m}^{-3},(\mathrm{O}) \sim 0.12 \mathrm{kmol} \mathrm{m}^{-3},(\boldsymbol{\Delta}) \sim 0.20 \mathrm{kmol} \mathrm{m}^{-3},(\boldsymbol{\nabla}) \sim 0.29$ $\mathrm{kmol} \mathrm{m}^{-3}$. Experimental data at various equilibrium BA concentrations in the aqueous phase were correlated to polynomial Eq. (9) and shown as a line in Fig. 3b. Data for pure dodecane were taken from Sabolová et al. (2001).

a

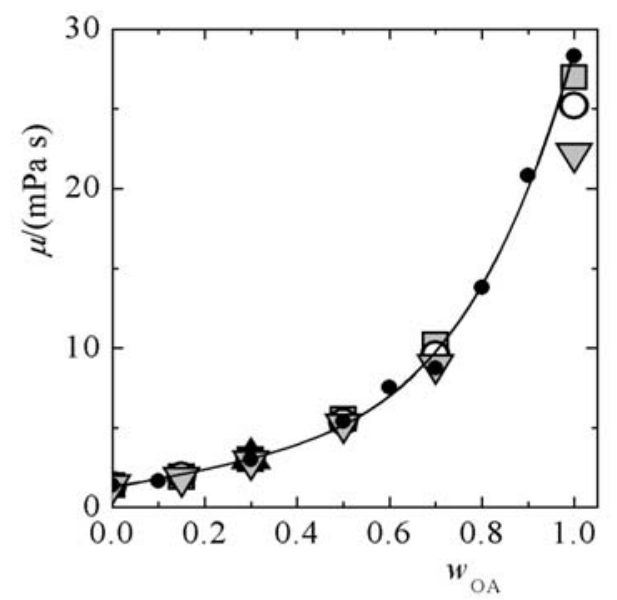

b

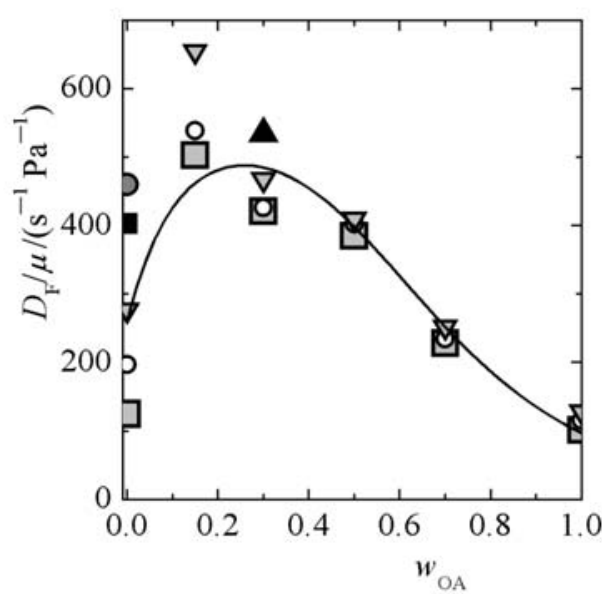

Fig. 4. Dependence of the viscosity of pure solvent and solvents containing BA at $25^{\circ} \mathrm{C}$ (a) and the ratio of the distribution coefficient and the solvent viscosity (b) on the mass fraction of oleyl alcohol in pure solvent. Full line in Fig. 4a represents the correlation according to Eq. (10). Full line in Fig. 4b is the calculated ratio based on Eqs. (9) and (10). Parameter

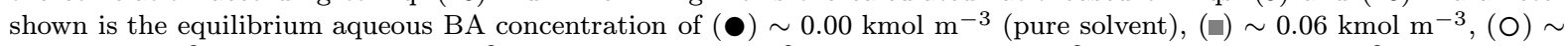
$0.12 \mathrm{kmol} \mathrm{m}^{-3},(\boldsymbol{\Delta}) \sim 0.20 \mathrm{kmol} \mathrm{m}^{-3},(\boldsymbol{\nabla}) \sim 0.29 \mathrm{kmol} \mathrm{m}^{-3},(\boldsymbol{\square}) \sim 0.37 \mathrm{kmol} \mathrm{m}^{-3},(\bigcirc) \sim 0.46 \mathrm{kmol} \mathrm{m}^{-3}$.

distribution coefficient with the increasing BA concentration was observed for solvents with the OA concentrations of 15 mass $\%$ and 30 mass $\%$, similarly to the results of BA extraction equilibriums with pure dodecane (Sabolová et al., 2001). No dependence of the distribution ratio on the equilibrium concentration of BA was observed at higher OA concentrations. The distribution coefficient of BA in the solvents increased with the increasing OA concentration. This increase was steeper at lower OA concentrations. For instance, at the equilibrium concentration of $0.12 \mathrm{kmol} \mathrm{m}^{-3}$ of $\mathrm{BA}$, the distribution coefficient in a 20 mass \% OA solvent was 1.08 (37\% of the distribution coefficient of pure OA, 2.90), while the distribution coefficient of pure dodecane at this concentration was only 0.274 .

Values of the distribution coefficients for various solvents were correlated with empirical Eq. (9) with coefficients presented in Table 3.

$$
D_{\mathrm{F}}=a_{1} w_{\mathrm{OA}}^{2}+a_{2} w_{\mathrm{OA}}+a_{3}
$$


Table 3. Coefficients of Eqs. (9) and (10)

\begin{tabular}{lc}
\hline Parameter & Value \\
\hline$a_{1}$ & -1.97 \\
$a_{2}$ & 4.41 \\
$a_{3}$ & 0.34 \\
$R_{\mathrm{a}}^{2}$ & 0.962 \\
\hline$b_{1} /(\mathrm{Pa} \mathrm{s})$ & $3.69 \times 10^{-2}$ \\
$b_{2} /(\mathrm{Pa} \mathrm{s})$ & $-2.34 \times 10^{-2}$ \\
$b_{3} /(\mathrm{Pa} \mathrm{s})$ & $9.82 \times 10^{-3}$ \\
$b_{4} /(\mathrm{Pa} \mathrm{s})$ & $4.02 \times 10^{-3}$ \\
$b_{5} /(\mathrm{Pa} \mathrm{s})$ & $1.31 \times 10^{-3}$ \\
$R_{\mathrm{b}}^{2}$ & 0.997 \\
\hline
\end{tabular}

Dependence of the solvent viscosity on the OA concentration is presented in Fig. 4a. Data for pure solvent (no BA) and the equilibrium loaded solvent phases are also included. As shown, extracted BA decreases the solvent viscosity from $28.3 \mathrm{mPa}$ s for pure $\mathrm{OA}$ to $22.2 \mathrm{mPa}$ s for $\mathrm{OA}$ in equilibrium with the $\mathrm{BA}$ solution with the concentration of $0.29 \mathrm{kmol} \mathrm{m}^{-3}$. The decrease of the solvent viscosity at lower OA concentrations in the solvents is less significant. A steep decrease in the viscosity was observed when a relatively small amount of dodecane was added to the OA solution. By diluting OA with dodecane to an 80 mass $\%$ solution, its viscosity decreased by $51 \%$. The dependence of the viscosity of pure solvents without BA was correlated using the empirical Eq. (10) with coefficients presented in Table 3 .

$$
\mu=b_{1} w_{\mathrm{OA}}^{4}+b_{2} w_{\mathrm{OA}}^{3}+b_{3} w_{\mathrm{OA}}^{2}+b_{4} w_{\mathrm{OA}}+b_{5}
$$

The ratio of the distribution coefficient and the solvent viscosity was suggested as a complex parameter for the evaluation of the solvent potential as the membrane phase governing its extraction and masstransfer properties. The dependence of this parameter on the OA concentration is shown in Fig. $4 \mathrm{~b}$ together with the calculated dependence of this parameter using the correlated dependences of $D_{\mathrm{F}}$ for various equilibrium BA concentrations and $\mu$ for pure solvents without BA on $w_{\mathrm{OA}}$ in Figs. $2 \mathrm{~b}$ and 3a, Eqs. (9) and (10). A clear maximum in this dependence can be observed either at 30 mass $\%$ of OA for the calculated dependence line or at 15 mass $\%$ (or possibly lower) for the experimental points. Because of the relatively low viscosity of 15 mass $\%$ and 30 mass \% OA phases, a slight increase of the distribution coefficient due to the increased BA concentration in the aqueous solution for these phases (Fig. 3a) contributes significantly to values of the $D_{\mathrm{F}} / \mu$ parameter, resulting in a large difference between the predicted line and individual $D_{\mathrm{F}} / \mu$ based on experimental values at higher BA concentrations. On the other hand, the viscosity change for pure OA and its 70 mass \% solution caused by the

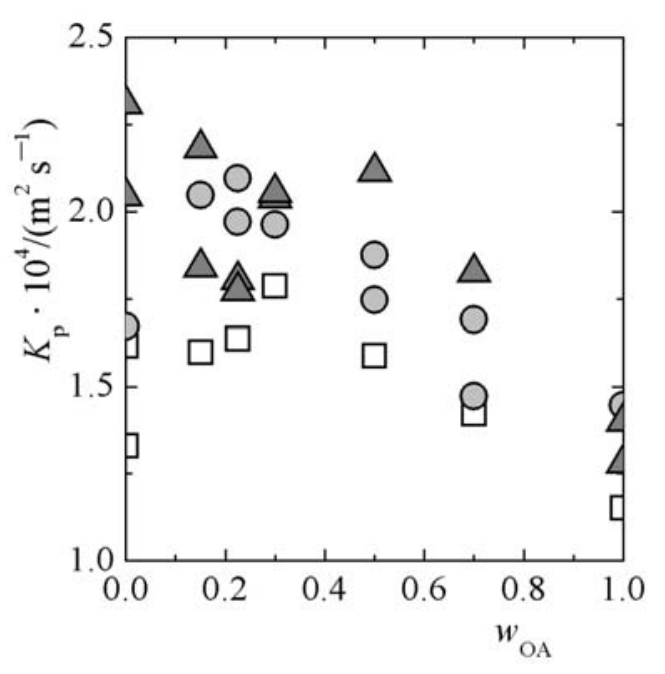

Fig. 5. Dependence of overall mass-transfer coefficient on the mass fraction of oleyl alcohol in pure solvent for various driving force values: $(\boldsymbol{\Delta}) \sim 0.45 \mathrm{kmol} \mathrm{m}^{-3},(\odot) \sim 0.3$ $\mathrm{kmol} \mathrm{m}^{-3},(\square) \sim 0.12 \mathrm{kmol} \mathrm{m}^{-3}$.

extracted BA shown in Fig 4a had no major impact on the respective values of the $D_{\mathrm{F}} / \mu$ ratio which correlate well the calculated line using viscosities of pure solvents, Fig $4 \mathrm{~b}$. The relative increase of the $D_{\mathrm{F}} / \mu$ ratio with the increasing equilibrium concentrations of $\mathrm{BA}$ is higher for solvents with lower OA concentration, Fig. 4b.

This is most significant for pure dodecane, where the BA concentration dependence of the distribution coefficient changes the value of the ratio significantly. It is obvious that by increasing the BA concentration, the maximum on the ratio dependence is shifted to lower concentrations of $\mathrm{OA}$ in the solvent, possibly even to pure dodecane at higher BA concentrations. More equilibrium experiments are needed for precise mapping of the ratio, especially at higher equilibrium BA concentrations for solvents with lower OA concentrations.

Selected organic phases in SLM were used in the pertraction of BA and their mass-transfer performance was evaluated. The dependence of the masstransfer coefficients on the OA concentration is presented in Fig 5. As it was shown, at the mean logarithmic concentration driving force of $0.12 \mathrm{kmol} \mathrm{m}^{-3}$ and $0.3 \mathrm{kmol} \mathrm{m}^{-3}, K_{\mathrm{p}}$ dependences pass a maximum at about 30 mass $\%$ and 20 mass $\%$ of OA in the membrane phase, respectively. At the mean logarithmic concentration driving force of $0.45 \mathrm{kmol} \mathrm{m}^{-3}$, no maximum was observed, with the highest $K_{\mathrm{p}}$ values for pure dodecane. Shifting of the apparent maximum in $K_{\mathrm{p}}$ towards pure dodecane by increasing the BA concentration is in agreement with the OA concentration dependence of the distribution coefficient/viscosity ratio discussed above. Also, the relative difference between the $K_{\mathrm{p}}$ values in Fig. 5 is more significant for the SLM phases containing less than 30 mass \% of 


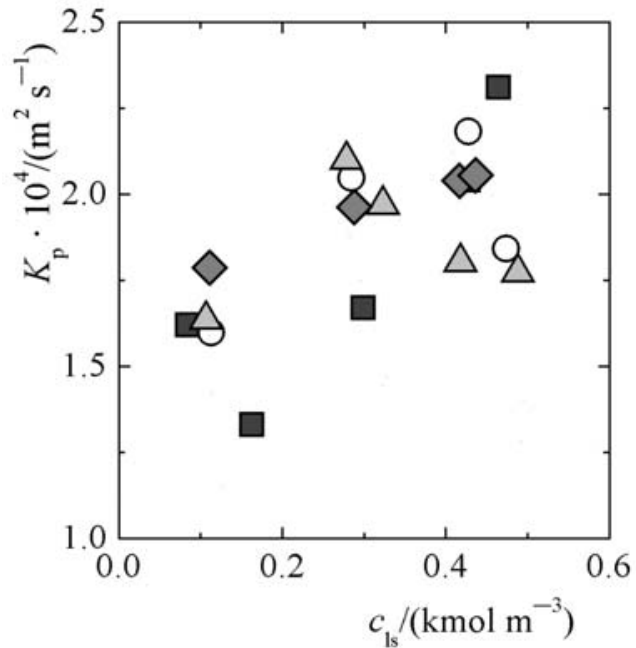

Fig. 6. Dependence of overall mass-transfer coefficient on the mean logarithmic driving force in the module, $c_{\mathrm{ls}}$, for various pure solvent compositions in mass \% of OA:

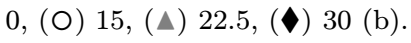

OA. This is better visible in Fig. 6, where the highest $K_{\mathrm{p}}$ value for individual SLM was obtained for 30 mass $\%$ of $\mathrm{OA}$ at lower driving force. By increasing the BA concentration to $0.45 \mathrm{kmol} \mathrm{m}^{-3}, K_{\mathrm{p}}$ increases more rapidly for lower OA concentration SLMs, with the highest marginal increase for pure dodecane. This is caused by coupled effect of similar concentration dependences of the distribution ratio in different membrane phases of various viscosities. Similar results were observed (Marták et al., 2011) when comparing the mass-transfer properties of pure dodecane and the dodecane solution of ionic liquid Cyphos IL-104 as the carrier of BA. In this paper, for the concentration driving force below $0.40 \mathrm{kmol} \mathrm{m}^{-3}$, the IL solution is preferable while at higher BA concentration in the feed, the dodecane SLM exhibited comparable or higher transport rates. The authors discussed this effect considering the differences in the values of the distribution coefficient which is highly preferable for SLM containing IL at lower BA concentrations and higher diffusion coefficients of transported BA molecules compared to BA complexes with IL (larger aggregates) in SLM.

\section{Conclusions}

A mild increase of the BA distribution coefficient, $D_{\mathrm{F}}$, with the increasing BA concentration in the aqueous phase for solvents with lower OA concentrations, and a strong increase of $D_{\mathrm{F}}$ with the OA concentration in the solvent were observed. At higher OA concentrations in the solvent, only a small OA concentration and no BA concentration dependences of the distribution coefficient were observed.

The ratio of the solute distribution coefficient and the solvent viscosity, $D_{\mathrm{F}} / \mu$, characterizes the extrac- tion and transport properties of the system and it is a useful parameter for preliminary evaluation of the solvent potential of an SLM or for its formulation. A maximum on the $\mathrm{OA}$ concentration dependence line of this ratio can be observed at the OA concentration of 15 mass \% to 30 mass \%. With the increasing BA concentration, the value of the $D_{\mathrm{F}} / \mu$ ratio increased for the 15 mass $\%$ and 30 mass $\%$ OA concentration and the most significant increase of this ratio was observed for pure dodecane. At the same time, the maximum on this ratio dependence was shifted towards lower OA concentrations, possibly even to pure dodecane. OA concentration dependence of the overall mass-transfer coefficient, $K_{\mathrm{p}}$, for SLMs exhibited also a maximum at the lower BA concentration driving force of $0.12 \mathrm{kmol} \mathrm{m}^{-3}$ and $0.3 \mathrm{kmol} \mathrm{m}^{-3}$ for the liquid membrane with about 30 mass $\%$ and 20 mass $\%$ of OA, respectively. At the higher BA concentration of $0.45 \mathrm{kmol} \mathrm{m}^{-3}$, no maximum was observed. At the BA concentration of about $0.45 \mathrm{kmol} \mathrm{m}^{-3}$ and higher, the highest $K_{\mathrm{p}}$ values were achieved for a pure dodecane membrane. Shifting of the maximum in the OA concentration dependence of $K_{\mathrm{p}}$ towards lower OA concentrations by increasing the BA concentration is in agreement with the $D_{\mathrm{F}} / \mu$ ratio dependences. The presented results show the potential of the $D_{\mathrm{F}} / \mu$ ratio in solvents screening and optimization of the SLM composition because the estimation of this ratio is much simpler than that of the $K_{\mathrm{p}}$ values. The presented analysis shows that the use of pure OA as a solvent or diluent is not preferable and a mixture of a low viscosity diluent with the OA concentration below 40 mass \% has to be used. Of course, increased temperature in the extraction or pertraction process can be advantageous due to the decreased viscosity of the solvent improving the mass-transfer rate.

Acknowledgements. Support of the Slovak grant agency VEGA No. 1-1184-11 is acknowledged.

\section{Symbols}

$A_{\mathrm{g}} \quad$ membrane support (module channel) geometric surface area $\mathrm{m}^{2}$

c molar concentration of undissociated acid $\mathrm{kmol} \mathrm{m}^{-3}$

$D_{\mathrm{F}} \quad$ distribution coefficient of solute on the feed interface defined by Eq. (3)

$\mathscr{D}$ diffusion coefficient of solute $\mathrm{m}^{2} \mathrm{~s}^{-1}$

$K_{\mathrm{p}} \quad$ overall mass-transfer coefficient in pertraction $\mathrm{m} \mathrm{s}^{-1}$

$k$ individual mass-transfer coefficient $\mathrm{m} \mathrm{s}^{-1}$ $\dot{n}$ molar flux $\mathrm{kmol} \mathrm{s}^{-1}$ $\mathrm{p} K_{\mathrm{a}} \quad$ negative decadic logarithm of acid dissociation constant

$R \quad$ mass transfer resistance $\quad \mathrm{s} \mathrm{m}^{-1}$ $R^{2} \quad$ goodness of fit 
$R_{\mathrm{p}} \quad$ overall mass-transfer resistance in pertraction

$T$ temperature

$t \quad$ time

$w \quad$ mass fraction

$\delta_{\mathrm{w}}$ thickness of the PTFE support for the SLM

$\varepsilon \quad$ porosity of the SLM support

$\mu \quad$ dynamic viscosity

$\tau \quad$ tortuosity of the support pores

\section{Subscripts and superscript}

F feed (donor phase)

in input value (to the PTFE module)

$\mathrm{k} \quad$ related to the kinetics

ls logarithmic mean value

$\mathrm{M} \quad$ liquid membrane

OA oleyl alcohol

out output value (from the PTFE module)

$\mathrm{R} \quad$ stripping solution

* in equilibrium

\section{Abbreviations}

BA butyric acid

LA lactic acid

OA oleyl alcohol

SLM supported liquid membrane

\section{References}

Bilgin, M. (2006). Phase equilibria of liquid (water + butyric acid + oleyl alcohol) ternary system. The Journal of Chemical Thermodynamics, 38, 1634-1639. DOI: 10.1016/j.jct.2006.03.017.

Bilgin, M., Kirbaşlar, Ş. İ., Özcan, Ö., \& Dramur, U. (2006). Distribution of butyric acid between water and several solvents. Journal of Chemical \& Engineering Data, 51, 15461550. DOI: $10.1021 /$ je060025z.

Blahušiak, M., Schlosser, S., \& Marták, J. (2010). Simulation of a hybrid fermentation-separation process for production of butyric acid. Chemical Papers, 64, 213-222. DOI: 10.2478/s11696-009-0114-7.

Blahušiak, M., Schlosser, Š., \& Marták, J. (2011). Extraction of butyric acid by a solvent impregnated resin containing ionic liquid. Reactive and Functional Polymers, 71, 736-744. DOI: 10.1016/j.reactfunctpolym.2011.04.002.

Evans, P. J., \& Wang, H. Y. (1988). Enhancement of butanol formation by Clostridium acetobutylicum in the presence of decanol-oleyl alcohol mixed extractants. Applied and Environmental Microbiology, 54, 1662-1667.

Evans, P. J., \& Wang, H. Y. (1990). Effects of extractive fermentation on butyric acid production by Clostridium acetobutylicum. Applied Microbiology and Biotechnology, 32, 393397. DOI: $10.1007 /$ bf00903771.

Grzenia, D. L., Schell, D. J., \& Wickramasinghe, S. R. (2012a). Membrane extraction for detoxification of biomass hydrolysates. Bioresource Technology, 111, 248-254. DOI: 10.1016/j.biortech.2012.01.169.

Grzenia, D. L., Wickramasinghe, S. R., \& Schell, D. J. (2012b). Fermentation of reactive-membrane-extracted and ammonium-hydroxide-conditioned dilute-acid-pretreated corn stover. Applied Biochemistry and Biotechnology, 166, 470-478. DOI: $10.1007 / \mathrm{s} 12010-011-9442-5$.

Hatzinikolaou, D. G., \& Wang, H. Y. (1992). Extractive fermentation systems for organic acids production. The Canadian Journal of Chemical Engineering, 70, 543-552. DOI: 10.1002/cjce.5450700318.

Ingale, M. N., \& Mahajani, V. V. (1994). Recovery of butyric acid, valeric acid, and caproic acid (BVC acids) from an aqueous waste stream using tributylphosphate (TBP) as an extractant. Separations Technology, 4, 252-257. DOI: 10.1016/0956-9618(94)80030-8.

Ingale, M. N., \& Mahajani, V. V. (1996). Recovery of carboxylic acids, $\mathrm{C}_{2}-\mathrm{C}_{6}$, from an aqueous waste stream using tributylphosphate(TBP): Effect of presence of inorganic acids and their sodium salts. Separations Technology, 6, 1-7. DOI: 10.1016/0956-9618(95)00132-8.

Kertész, R., Schlosser, Š., \& Šimo, M. (2004). Mass-transfer characteristics of a spiral-channel SLM module in pertraction of phenylalanine. Desalination, 163, 103-117. DOI: 10.1016/s0011-9164(04)90182-8.

Keshav, A., Wasewar, K. L., \& Chand, S. (2009). Extraction of acrylic, propionic, and butyric acid using Aliquat 336 in oleyl alcohol: Equilibria and effect of temperature. Industrial \& Engineering Chemistry Research, 48, 888-893. DOI: 10.1021/ie8010337.

Li, Z. Y., Qin, W., \& Dai, Y. Y. (2002). Liquid-liquid equilibria of acetic, propionic, butyric, and valeric acids with trioctylamine as extractant. Journal of Chemical \& Engineering Data, 47, 843-848. DOI: 10.1021/je015526t.

Marták, J., Schlosser, Š., Sabolová, E., Krištofíková, L., \& Rosenberg, M. (2003). Fermentation of lactic acid with $R h i$ zopus arrhizus in a stirred tank reactor with a periodical bleed and feed operation. Process Biochemistry, 38, 15731583. DOI: 10.1016/s0032-9592(03)00059-1.

Marták, J., \& Schlosser, S. (2007). Extraction of lactic acid by phosphonium ionic liquids. Separation and Purification Technology, 57, 483-494. DOI: 10.1016/j.seppur.2006.09.013.

Marták, J., \& Schlosser, S. (2008). Liquid-liquid equilibria of butyric acid for solvents containing a phosphonium ionic liquid. Chemical Papers, 62, 42-50. DOI: 10.2478/s11696-0070077-5.

Marták, J., Schlosser, Š., \& Vlčkova, S. (2008). Pertraction of lactic acid through supported liquid membranes containing phosphonium ionic liquid. Journal of Membrane Science, 318, 298-310. DOI: 10.1016/j.memsci.2008.02.064.

Marták, J., Schlosser, Š., \& Blahušiak, M. (2011). Mass-transfer in pertraction of butyric acid by phosphonium ionic liquids and dodecane. Chemical Papers, 65, 608-619. DOI: 10.2478/s11696-011-0069-3.

Reid, R. C., Prausnitz, J. M., \& Sherwood, T. K. (1977). The properties of gases and liquids (3rd ed.). New York, NY, USA: McGraw-Hill.

Sabolová, E., Schlosser, Š., \& Marták, J. (2001). Liquid-liquid equilibria of butyric acid in water + solvent systems with trioctylamine as extractant. Journal of Chemical $\&$ Engineering Data, 46, 735-745. DOI: 10.1021/je000323a.

Shan, X. C., Qin, W., \& Dai, Y. Y. (2006). Dependence of extraction equilibrium of monocarboxylic acid from aqueous solutions on the relative basicity of extractant. Chemical Engineering Science, 61, 2574-2581. DOI: 10.1016/j.ces.2005.11. 026.

Vandák, D., Zigová, J., Šturdik, E., \& Schlosser, S. (1997). Evaluation of solvent and $\mathrm{pH}$ for extractive fermentation of butyric acid. Process Biochemistry, 32, 245-251. DOI: 10.1016/s0032-9592(96)00084-2. 
Wilke, C. R., \& Chang, P. (1955). Correlation of diffusion coefficients in dilute solutions. AIChE Journal, 1, 264-270. DOI: 10.1002/aic.690010222.

Wu, Z. T., \& Yang, S. T. (2003). Extractive fermentation for butyric acid production from glucose by Clostridium tyrobutyricum. Biotechnology and Bioengineering, 82, 93-102. DOI: $10.1002 /$ bit.10542.

Zigová, J., Vandák, D., Schlosser, Š., \& Šturdík, E. (1996). Extraction equilibria of butyric acid with organic solvents. Separation Science and Technology, 31, 2671-2684. DOI: 10.1080/01496399608000819.
Zigová, J., Šturdík, E., Vandák, D., \& Schlosser, Š. (1999). Butyric acid production by Clostridium butyricum with integrated extraction and pertraction. Process Biochemistry, 34, 835-843. DOI: 10.1016/s0032-9592(99)00007-2.

Zigová, J., Švitel, J., \& Šturdík, E. (2000). Possibilities of butyric acid production by butanol oxidation with Gluconobacter oxydans coupled with extraction. Chemical $\&$ Biochemical Engineering Quarterly, 14, 95-100. 